\title{
CORRELATION BETWEEN BIRTH WEIGHT AND CLINICAL FINDINGS IN DIPLEGIA
}

\author{
BY \\ ELSPETH M. RUSSELL \\ From the Department of Child Life and Health, Edinburgh, and \\ Edinburgh Clinic, Scottish Council for Care of Spastics
}

(RECEIVED FOR PUBLICATION MARCH 4, 1960)

Since the time of Little the role of birth injury in the aetiology of cerebral palsy has been much debated (Little, 1843; 1862). Freud and Collier believed that diplegia often had its origin in prenatal life and was less frequently the result of birth injury than was generally thought (Freud, 1897; Collier, 1899, 1924). More recently attempts have been made to classify diplegic patients into two main groups:

(1) Those who are delivered prematurely and who tend to suffer from paraplegia. This group shows, on the whole, normal intelligence and no other neurological abnormalities.

(2) Those of approximately average birth weight who show upper as well as lower limb involvement. This group tends to show mental impairment and other neurological defects (Childs and Evans, 1954; Churchill, 1958; Polani, 1958).

The birth weight distributions of patients suffering from congenital paraplegia or tri- and tetraplegia are generally found to be biphasic. It has been suggested that this provides further evidence in favour of there being two major aetiological groups of diplegic patients (Childs and Evans, 1954).

In the present study, the birth weight distribution of 200 diplegic patients was analysed and correlated with the clinical findings.

\section{Terminology}

Diplegia is used to describe a more or less symmetrical paresis of cerebral origin, more severe in the lower limbs than in the upper. The paresis may be accompanied by hypotonia, rigidity or spasticity of the affected limbs. Patients with marked involuntary movements or ataxia were not included. The patients were placed in two categories:

(1) Paraplegics, in whom the upper limbs were functionally normal, even though minor neurological abnormalities were apparent in them.
(2) Tri- and tetraplegics in whom there was some functional involvement of one or both upper limbs (Balf and Ingram, 1955).

\section{Selection of Patients and Methods of Study}

The series comprised 200 diplegic children referred to the Edinburgh Clinic of the Scottish Council for Care of Spastics; $58.5 \%$ were males and $41.5 \%$ females. Their ages ranged from 14 months to 13 years.

Patients may be referred to this clinic by school medical officers or general practitioners from any part of Scotland. Since many patients were sent because they were believed to be suitable candidates for a special school designed to cater for severely physically affected children of average intelligence, the series was highly preselected. At the clinic detailed histories were taken and examinations made by a neurologist, psychologist and orthopaedic surgeon. In addition to having access to the records of the clinic the parents were interviewed and patients examined personally in all but a few instances. Any patients in whom a postnatal cause for the condition was probable were excluded.

\section{Findings}

Birth Weights. Birth weights were obtained in the majority of cases from hospital or nursing home records and in the remainder from questioning parents. The mean birth weight of 88 paraplegic patients was $5 \cdot 1 \mathrm{lb}$. (S.D. $0 \cdot 23$ ), and of 112 tri- and tetraplegic patients was $6 \cdot 1 \mathrm{lb}$. (S.D. 0.2). The frequency distribution of birth weights in both groups shows a bimodal curve (Fig. 1). The distribution of birth weights in the general population showing a unimodal curve is given for comparison. This distribution was obtained from a series of live births in an Edinburgh hospital (Drillien and Richmond, 1956), allowance then being made for infant mortality. The paraplegics show a major peak at about $4 \mathrm{lb}$. and a smaller one at $8 \mathrm{lb}$. In the tri- 


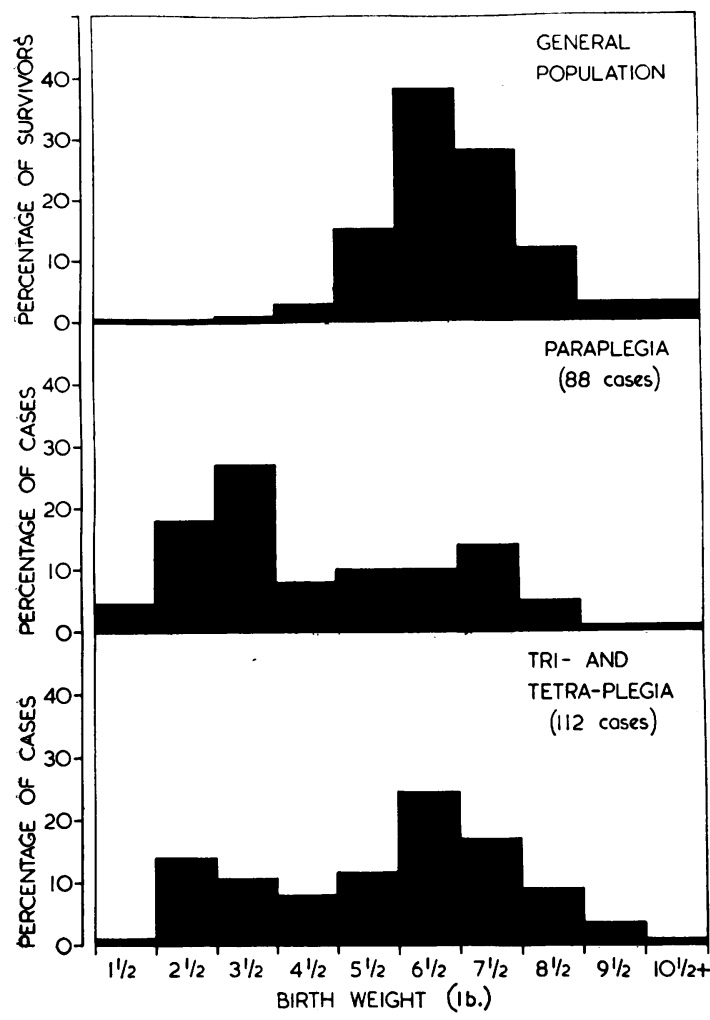

FIG. 1.-Distribution of birth weights in two groups of diplegic patients compared to the distribution in the general population.

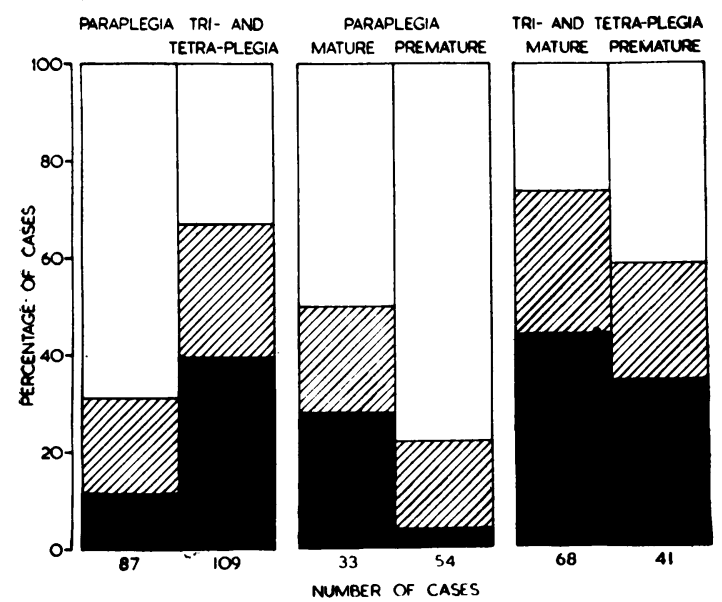

FIG. 2.-Comparative intelligence of mature and premature paraplegic, tri- and tetraplegic patients.

$\square$ normal $W / /$, , retarded $\square$ ineducable and tetraplegic group on the other hand, the main peak is in the region of $7 \mathrm{lb}$. with a lesser rise at $3 \mathrm{lb}$. Thus paraplegic patients, as a group, tend to be premature, whereas patients with upper limb involvement tend towards average birth weights.

Intelligence. The intelligence of the two groups was compared on the basis of the psychologist's assessment and patients were divided into three groups:

(1) 'Normal': Those educable at a normal school or a special school catering for children of average intelligence but with physical handicaps. Arbitrarily, children with an I.Q. of 80 or above were placed in this category.

(2) 'Retarded': Those unlikely to benefit from education at schools for children of average intelligence and who were usually best placed in schools for the mentally or physically handicapped. The majority in this group have an I.Q. above 60 but below 80 .

(3) 'Ineducable': Patients whom it is impossible to educate, some of whom may be suitable for training in occupation centres. An I.Q. of less than 60 forms the criterion for classifying patients in this category.

Four children, who were considered too young for an estimate of educability to be made were excluded from the analysis. From Fig. 2 and the Table it will be seen that paraplegic patients, as a group, are more intelligent than those with upper limb involvement. The difference between these two groups is highly significant statistically ( $p=$ $<0.001)$. If the patients are further subdivided into mature and premature (the criterion of prematurity being a birth weight of $5 \frac{1}{2} \mathrm{lb}$. or less), it is evident that, within each group, patients of smaller birth weight tend to be more intelligent than those of larger birth weight. However, although the difference between the mature and premature paraplegics is significant $(p=0.01)$, there is not a statistically significant difference between the two groups of tri- and tetraplegic patients.

Epilepsy. The incidence of epilepsy among paraplegic patients was $9 \%$ (eight cases in 88 ), whereas in the tri- and tetraplegic group it was $26.8 \%$ (30 cases in 112).

Strabismus. No significant difference was found in the incidence of strabismus in the two groups.

As a corollary to the above findings one would expect the birth weight distribution of patients with mental defect and/or other neurological abnormalities (who are thought to represent a distinct 
TABLE

INTELLIGENCE OF PARAPLEGICS AND TRI- AND TETRAPLEGICS

\begin{tabular}{|c|c|c|c|c|c|c|c|}
\hline Group & & & & $\begin{array}{l}\text { No. of } \\
\text { Cases }\end{array}$ & $\underset{(\%)}{\text { Normal }}$ & $\underset{(\%)}{\text { Retarded }}$ & Ineducable \\
\hline 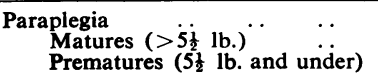 & $\begin{array}{l}\cdots \\
\cdots \\
\cdots\end{array}$ & $\begin{array}{l}\cdots \\
\cdots \\
\cdots\end{array}$ & $\begin{array}{l}\cdots \\
\cdots \\
\cdots\end{array}$ & 87 & $68 \cdot 9$ & $19 \cdot 6$ & $11 \cdot 5$ \\
\hline 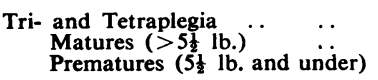 & $\begin{array}{l}\cdots \\
\cdots \\
\cdots\end{array}$ & $\begin{array}{l}\cdots \\
\cdots \\
\cdots\end{array}$ & $\begin{array}{l}\cdots \\
\cdots \\
\cdots\end{array}$ & $\begin{array}{l}68 \\
41\end{array}$ & $\begin{array}{l}26 \cdot 5 \\
41 \cdot 5\end{array}$ & $\begin{array}{l}29 \cdot 4 \\
24 \cdot 4\end{array}$ & $\begin{array}{l}44 \cdot 1 \\
34 \cdot 2\end{array}$ \\
\hline
\end{tabular}

group) to show a unimodal curve. Similarly, the birth weight distribution of patients of normal intelligence who are without other neurological defects should also be unimodal (Churchill, 1958; Polani, 1959). When birth weights in these groups were analysed, the bimodality became less marked, but did not entirely disappear (Fig. 3).

The mean birth weights of the two groups differed, being $6 \cdot 1 \mathrm{lb}$. (S.D. 3.1) in patients showing mental impairment and/or epilepsy and $5.0 \mathrm{lb}$. (S.D. 3.7) in the group which did not show these abnormalities.

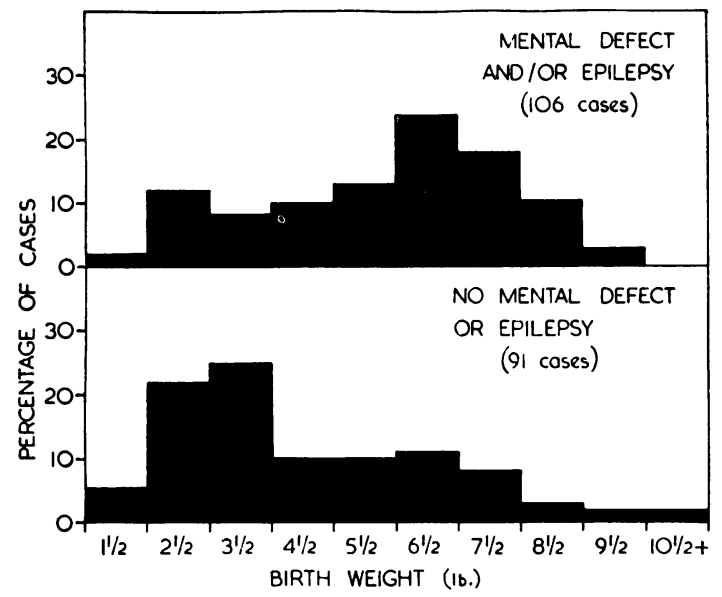

FIG. 3.-Distribution of birth weights related to presence or absence of mental defect and epilepsy.

\section{Discussion}

When birth weights of a group of paraplegic patients and a group of tri- and tetraplegic patients were analysed the distributions in each group were bimodal. Paraplegic patients tended to be smaller at birth, more intelligent and less liable to complicating neurological abnormalities than those with upper limb involvement. Tri- and tetraplegic patients were larger at birth but more often suffered from mental retardation and epilepsy. The greater extent of their limb involvement and other clinical manifestations suggested that brain damage was more extensive than in those with paraplegia. It has been suggested that these differences in clinical findings may be correlated with differences in aetiology in the two groups. Both the premature birth and the relatively localized cerebral damage in the paraplegic patients may be the result of damaging factors operating in utero. Possibly the prematurity, per se, contributes to the cerebral palsy by depriving the nervous system of the intrauterine environment essential for its normal maturation (Polani, 1958). The more extensive cerebral involvement of the tri- and tetraplegic group may be attributed, in some cases, to birth trauma. However, even when there is a history of difficult delivery, birth trauma cannot necessarily be incriminated as foetal abnormality may have been the cause of the abnormal parturition.

\section{Summary}

The birth weights of 88 paraplegic patients and 112 tri- and tetraplegic patients were analysed and correlated with clinical findings. Patients with paraplegia, on the whole, were found to be considerably smaller at birth, more intelligent and showed a lower incidence of epilepsy than the group of patients with upper limb involvement. The distribution of birth weights in both groups was bimodal. When the birth weights of the entire group were analysed according to the presence or absence of mental defect and epilepsy, it was found that most of the patients with mental impairment or epilepsy were of average or high birth weights and tended to show upper as well as lower limb involvement. Those who showed no other neurological abnormalities tended to be paraplegic patients of premature birth. Patients with diplegia can be segregated into two fairly well defined groups which probably differ aetiologically as well as clinically.

I am indebted to the Scottish Council for Care of Spastics for granting facilities and financial support for this investigation and to their medical consultants in Edinburgh, Mr. G. A. Pollock, Dr. J. A. Naughton and Dr. T. T. S. Ingram, for allowing me to use their case 
notes. I am grateful to Professor R. W. B. Ellis and Dr. Ingram for advice in the preparation of this paper. My thanks are also due to Dr. C. M. Drillien for help with statistical analysis and to Miss B. Sinclair for secretarial assistance.

This work was done during tenure of a graduate research fellowship from the University of Edinburgh.

\section{REFERENCES}

Balf, C. L. and Ingram, T. T. S. (1955). Problems in the classification of cerebral palsy in childhood. Brit. med. J., 2, 163

Childs, B. and Evans, P. R. (1954). Birth weights of children with cerebral palsy. Lancet, 1,642 .
Churchill, J. A. (1958). The relationship of Little's disease to premature birth. Amer. J. Dis. Child., 96, 32.

Collier, J. S. (1899). Cerebral diplegia. Brain, 22, 373.

(1924). The pathogenesis of cerebral diplegia. Ibid., 47, 1.

Drillien, C. M. and Richmond, F. (1956). Prematurity in Edinburgh Arch. Dis. Childh., 31, 390 .

Freud, S. (1897). Die infantile Cerebrallähmung. Spec. Path Ther. Nothnagel, Vienna, 9, 2 Theil 2 Abtheilung, 6.

Little, W. J. (1843). Deformities of the human frame. Lancet,

1, 318. labours, premature birth, and asphyxia neonatorum on the mental and physical condition of the child, especially in relation to deformities. Trans. obstet. Soc. Lond., 3, 293.

Polani, P. E. (1958). Prematurity and 'cerebral palsy'. Brit. med. J., 2, 1497. (1959). Effects of abnormal brain development on function. Cerebral Palsy Bull., 7, 27. 